\title{
DIGITALIZED PRESERVATION AND PRESENTATION OF HISTORICAL BUILDING - TAKING TRADITIONAL TEMPLES AND DOUGONG AS EXAMPLES
}

\author{
W. B. Yang ${ }^{\mathrm{a}, \mathrm{b}}$ Y. N. Yen ${ }^{\mathrm{a} *}$, H. M. Cheng ${ }^{\mathrm{a}}$ \\ ${ }^{a}$ China University of Technology, 56 Sec. 3 Xinglong Rd., 116 Taipei, Taiwan - (wunbin, alexyen, hungmc)@ cute.edu.tw \\ ${ }^{\mathrm{b}}$ National Taipei University of Technology, 1, Sec. 3, Zhongxiao E. Rd., 106 Taipei, Taiwan - t103859001@ntut.edu.tw
}

KEY WORDS: Historical Building, Digital Archive, 3D Laser Scanning, Virtual Reality, Augmented Reality

\begin{abstract}
:
The integration of preservation of heritage and the digital technology is an important international trend in the 21st century. The digital technology not only is able to record and preserve detailed documents and information of heritage completely, but also brings the value-added features effectively. In this study, 3D laser scanning is used to perform the digitalized archives for the interior and exterior body work of the building which contains integration of 3D scanner technology, mobile scanning collaboration and multisystem reverse modeling and integration technology. The 3D model is built by combining with multi-media presentations and reversed modeling in real scale to perform the simulation of virtual reality (VR). With interactive teaching and presentation of augmented reality to perform the interaction technology to extend the continuously update in traditional architecture information. With the upgrade of the technology and value-added in digitalization, the cultural asset value can be experienced through 3D virtual reality which makes the information presentation from the traditional reading in the past toward user operation with sensory experience and keep exploring the possibilities and development of cultural asset preservation by using digital technology makes the presentation and learning of cultural asset information toward diversification.
\end{abstract}

\section{INTRODUCTION}

Preservation and reuse of heritage assets is the common universal values in 21st century which is one of the important national policies in our country. In 21st century, the concepts of preservation have big differences from the past, such as from the frozen preservation to activated reuse dynamic preservation and from the forced preservation led by government to public participating preservation. Those preservation concepts are discussed as follows,

1. Dynamic Preservation: Due to the rapid change of the environment, the traditional frozen preservation does not meet the need of the times. How to reuse and add values with activation to the repaired cultural assets becomes the necessary consideration.

2. Public Participation: The public participation affects the success of the preservation work directly. Therefore, inviting local people to participate in regulating local long term preservation policies and discuss the future direction of development to reach a consensus which is helpful for the continuation of local culture skills and heritages.

3. Modern technology: using the modern technology to assist in preservation, modification and marketing display of historical building is an important issue. How to integrate and apply various tools of "digital technology" in preservation effectively is a big concern of all countries.

“Quebec Declaration” passed in the 17th ICOMOS General Assembly states that "Considering that modern digital technologies (digital data bases, web sites) can be used efficiently and effectively at a low cost to develop multimedia inventories that integrate tangible and intangible elements of heritage, we strongly recommend their widespread use in order to better preserve, disseminate and promote heritage places and their spirit. These technologies facilitate the diversity and constant renewal of the documentation on the spirit of place." understanding technology, research and training is necessary.

\section{BACKGROUND}

Digitization and application technology of cultural heritage assets are discussed as follows,

\subsection{D Laser Scanning}

3D long-range laser scanners are non-contact and nondestructive measurement system to avoid damage caused by the pressure form from contacting the test materials. It also can reduce the amount of time required in measurement. This is a reverse engineering technology which is to measure the surface in a more rapid and accurate method. Data obtained from the 3D scanning comes from the body of the building directly and the point cloud (data obtained from the 3D scanner) has the features of real-time recording and live recording. (Shih, 2007) Therefore, the construction process of the digitalization established in this way is more accurate and reliable. (Bjoerk, 1993; Shih, 2002)

\subsection{Virtual Reality}

Virtual Reality is the simulation world created by the computer. Users can move freely in it and get feedback. Mayer (1999) believes that the virtual reality is not only a tool but a technology, media, as well as engine in connecting with the society. Users can understand the real world situation by

\footnotetext{
* Corresponding author.
} 
entering the virtual reality space. Virtual Reality let users to browse the information they need by human-computer interaction, then to promote the preservation of the cultural assets. Researchers also can understand the structure inside the building by this technology (Shih, 2010 ). Four elements required for composing the virtual reality are as follows (Burdea \& Coiffet, 2003) ,

1. (Immersion): An immersive experience is provided to users.

2. (Interaction): The feedback of human-computer interaction.

3. (Imagination): The impact of imagination is emphasized in the virtual reality with its application is designed for solving specific problems, including developers' ideas.

4. (Insight): The versatility of virtual reality meets the needs of various groups (from students to researchers), even it faces the different thinking of users about the virtual reality.

\subsection{Augmented Reality}

Augmented Reality has become the focus by the rapid progress of the digital communications technology in recent years. Augmented Reality is the extension of the virtual reality. For interaction, the virtual world is more close to the real world with induction equipment. Paul Milgram and Fumio Kishino, major in engineering of University of Toronto in Canada in 1994, defined the augmented reality and proposed the theory of "Reality-virtuality continuum" which is the mixed reality of the real and virtual environments. AR technology, proposed by Vassilios in 2001, is able to restore the damaged heritage and the plan is used in the arheoguide system. In the ruins of the Temple of Hera, tourists can see the original appearance of the temple through the mobile devices is shown in Figure 1. Fraunhofer IGD Research Center used AR technology on the mobile navigation since 2009. Tourists can see the pictures and text introduction of the building in each era by the mobile devices to understand the history and events of the historical buildings by AR technology is shown in Figure 2.

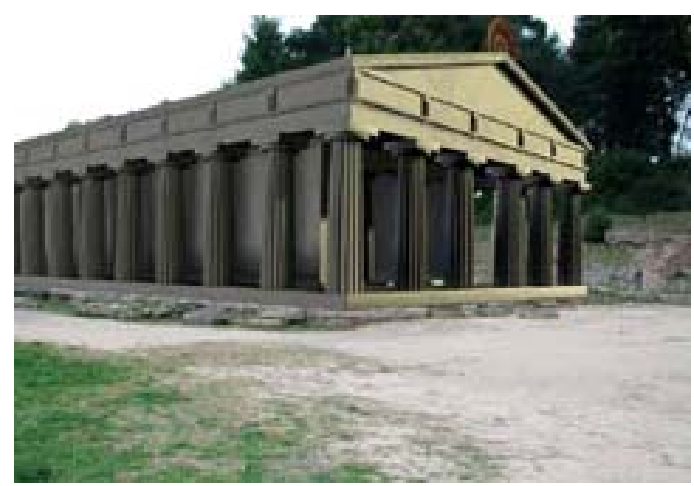

Figure 1. Arheoguide system (Vassilios, 2001)

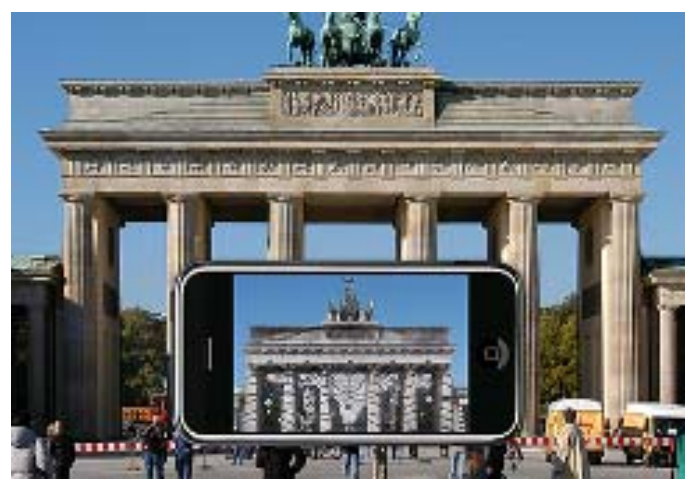

Figure 2. AR technology on the mobile navigation (Fraunhofer IGD, 2009)

\section{ESTABLISHMENT OF DIGITAL DATA OF HERITAGE}

In this study, "Integrated Technology of 3D Laser Image Capture of Heritage” is used for the digital archives work of Taipei Xia Hai City God Temple. The content includes integration of scanner technology, mobile scanning collaboration and multi-system reverse modeling and integration technology.

\subsection{D Laser Scanning Digitization:}

The 3D laser scanning equipment with high accuracy for this plan are two color FARO Photon 80 - Riegl z420i 3D scanners with mobile scanning device car carrier (10M) to perform a completed digital scanning for the higher altitude of the subject. (Figure 3) Sight vane system technology and on-site synchronous operation correction is used and the threedimensional imaging accuracy under $2 \mathrm{~cm}$ is controlled to obtain the high accuracy and completed digital data (Figure 4). In addition, the implementation and result of the work of the plan, elevation and section of CAD files based on the point cloud are shown in Figure 5.

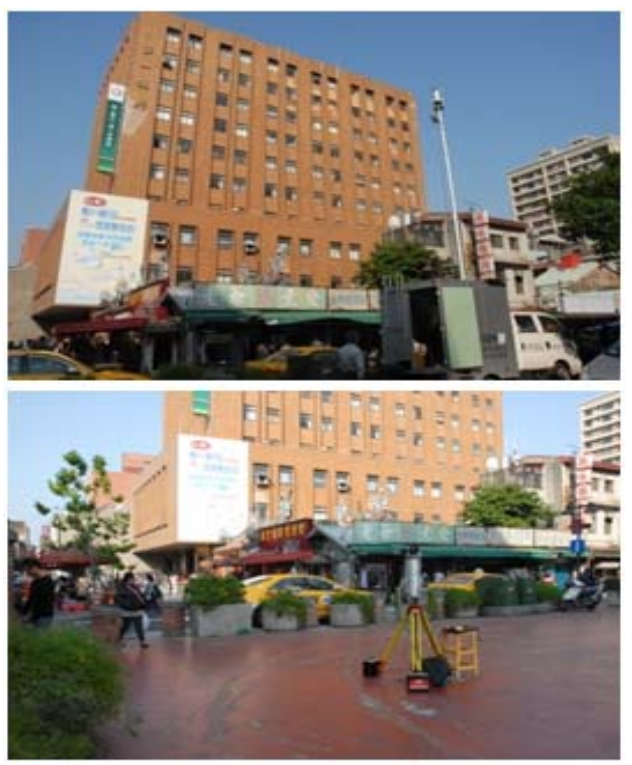

Figure 3. Scanners with mobile scanning device 

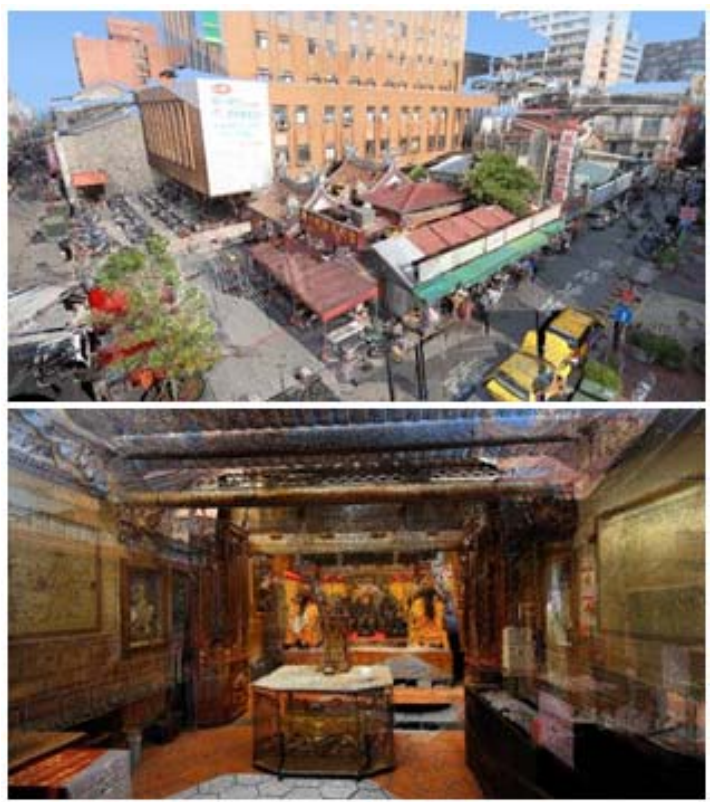

Figure 4. Digital data of 3D Laser Scanning
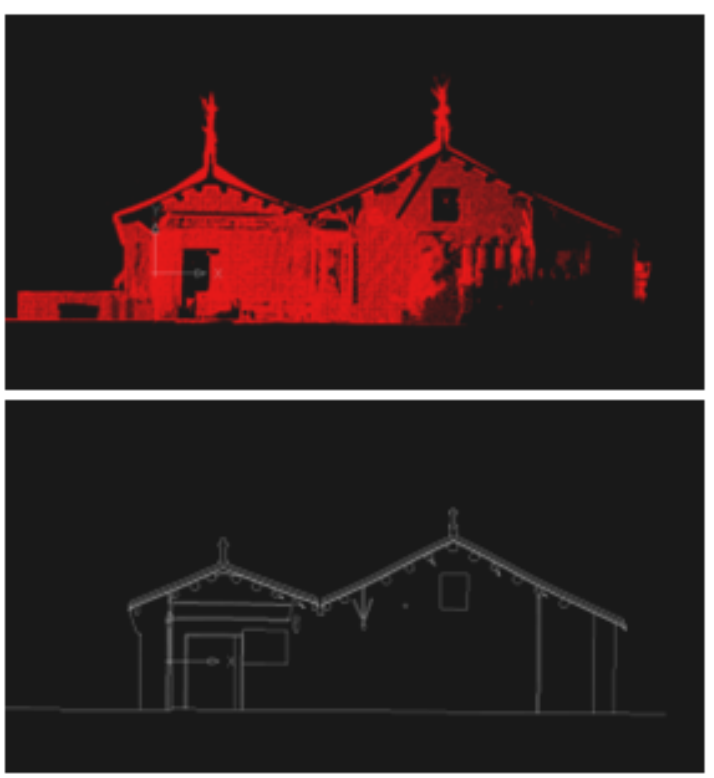

Figure 5. CAD files

\subsection{D Digitization Modeling}

Reverse engineering modeling is used in 3D models, using the digital data features of the accurate point cloud files which are based on scanning the construction with output ratio of $1: 1$ in restoring the actual body size on-site. The accuracy of the 3D model is effectively improved when comparing with the traditional data measured by post modeling. The point cloud files is transferred by file conversion technology to the 3D model editing software to perform the material setting and 3D modeling. The archive is more valuable and meaningful after the value-added process. The output model of Taipei Xia Hai City God Temple is shown in Figure 6 and Figure 7.

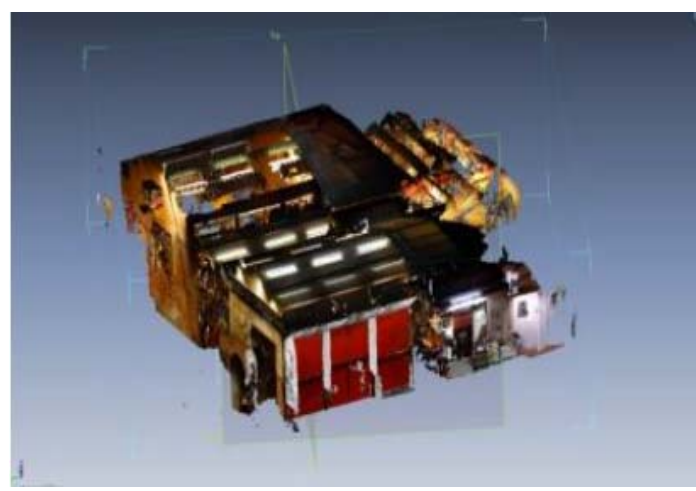

Figure 6. 3D data of Taipei Xia Hai City God Temple

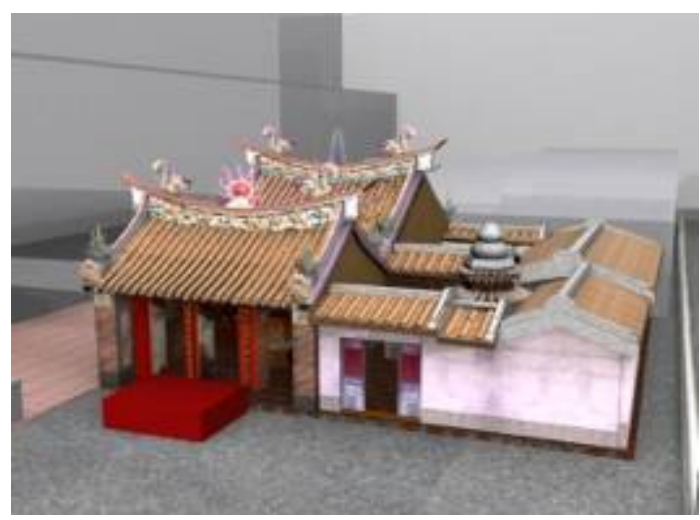

Figure 7. 3D model of Taipei Xia Hai City God Temple

\section{ESTABLISHMENT OF 3D VIRTUAL INTERACTION}

The research tool of "EON Studio" is used to produce the virtual reality for interaction establishment. Features of EON Studio are diversification in interaction establishment, ease of operation without program writing, gravity simulation and so on. In this study, the design process and actions of interaction for the Taipei Xia Hai City God Temple is as follows,

\subsection{Nodes Design for Interaction}

In this study, the design of a virtual human-computer interaction is using the Nodes in EON Studio. Details are shown in Figure 8 and Figure 9.

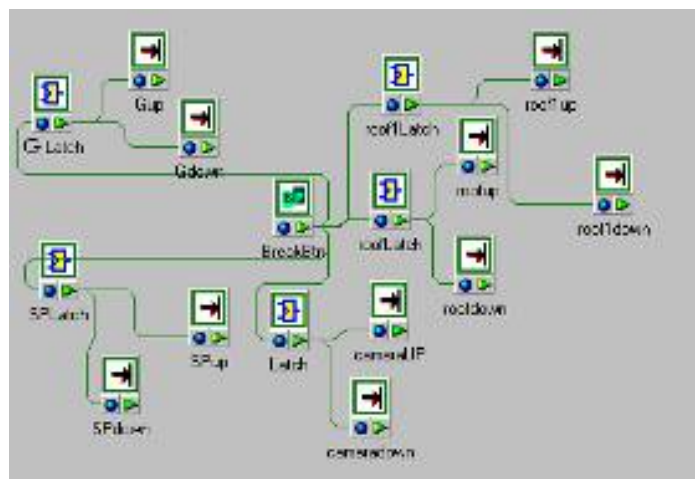

Figure 8. Actions of interaction for the Taipei Xia Hai City God Temple 


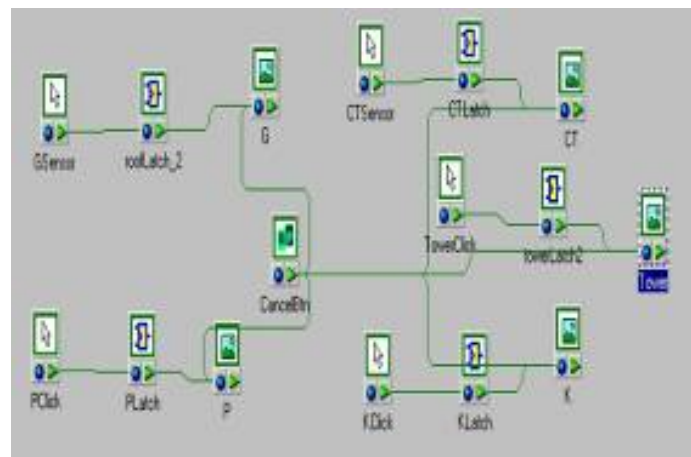

Figure 9. text of interaction for the Taipei Xia Hai City God Temple

\subsection{Human-computer Interface Design}

Based on the notes design, the interactive display of "component dismantling" and "component description" of Taipei Xia Hai City God Temple is provided for learning. The result is shown in Figure 10 and Figure 11

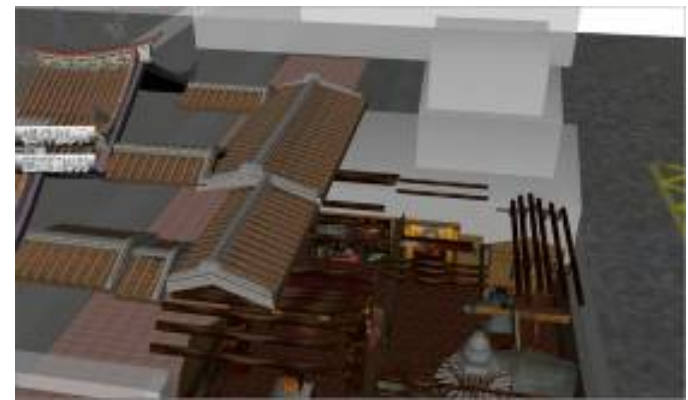

Figure 10. Component dismantling for the Taipei Xia Hai City God Temple
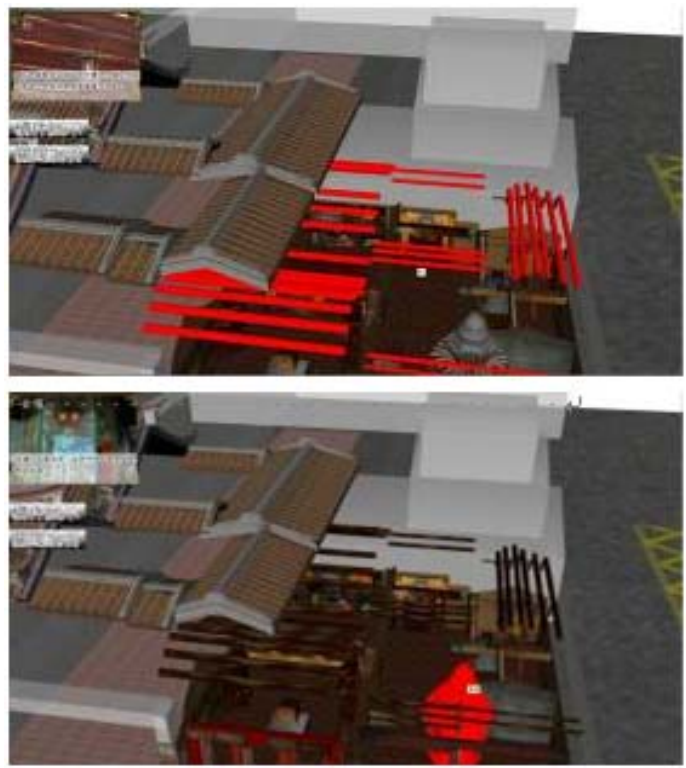

Figure 11. Component dismantling for the Taipei Xia Hai City God Temple

\section{AUGMENTED REALITY APPLICATION}

\subsection{The display of Heritage}

The AR technology is used for Taipei Xia Hai City God Temple in this study. The AR technology is displayed by monitors, using cameras to capture the mark (MARKER) and the combination of real and virtual images is shown on the monitors. The AR-Media software is used by three steps, pictures selection and production, model importing and setting and presentation setting. Value-added applications such as books, maps, tablets and so on can be combined as shown in Figure 12.
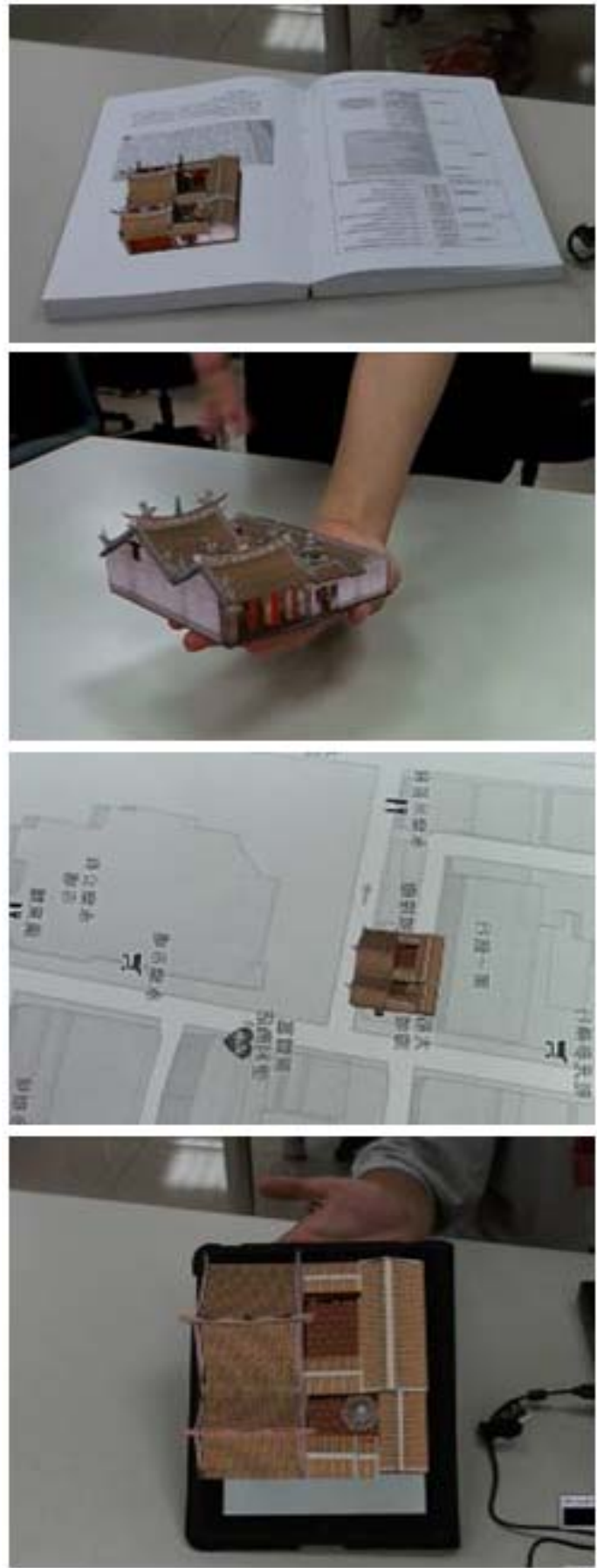

Figure 12. Value-added applications of AR 


\subsection{Application in Dougong components}

Dougong is the unique wooden structure in Chinese architecture which is composed with square wood of Doug and elongated wood of Ong and is located on the stigma and beams. Doug and Ong can be used together to undertake the roof and transmitted the weight to the beams. In the traditional architecture, Dougong is an important nodes which has different components and combination due to the location. This system is based on the "Picture, Symbol and Image Recognition" method to design the AR digitalized navigation system by different Dougong components. Methods and procedure are as follows,

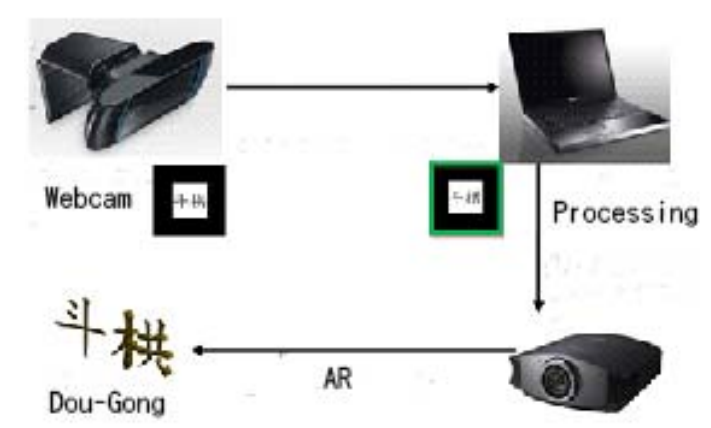

Figure 13. AR digitalized navigation system for Dougong

With the advantages of AR system, users not only can experience the most authentic environments of historic heritages, but also can obtain intuitive, interactive visual navigation information. Augmented Reality System provides a new, convenient and digitized choice to combine 3D objects in a single window for experiencers to navigate the presentation of pictures in a convenient and easy way and reduce the errors. c presented by the pictures helps users to understand each link and assembly methods of the traditional wooden Dougong and enhance users" understanding in the "shape" and the "composition" of the Dougong.

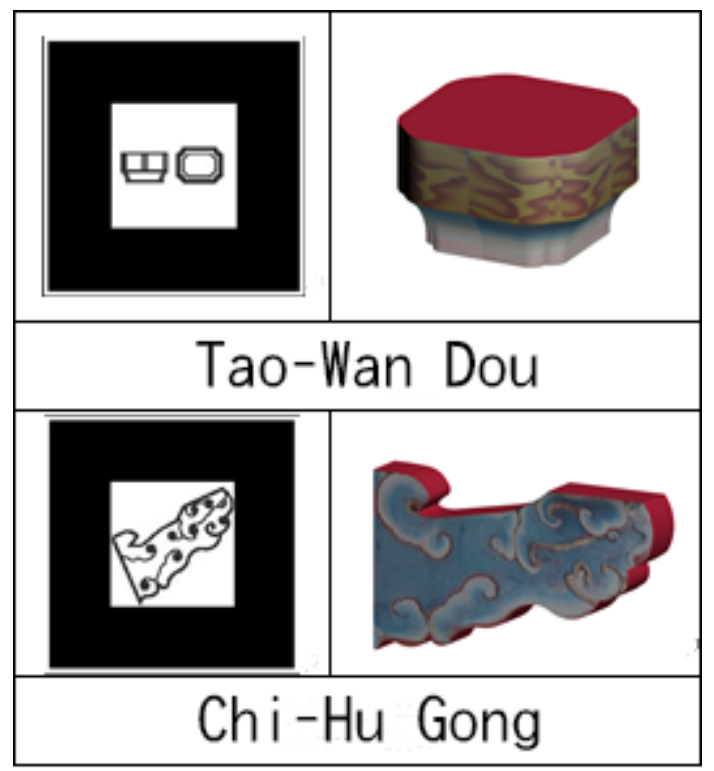

Figure 14. Tao-Wan Dou and Chi-Hu Gong

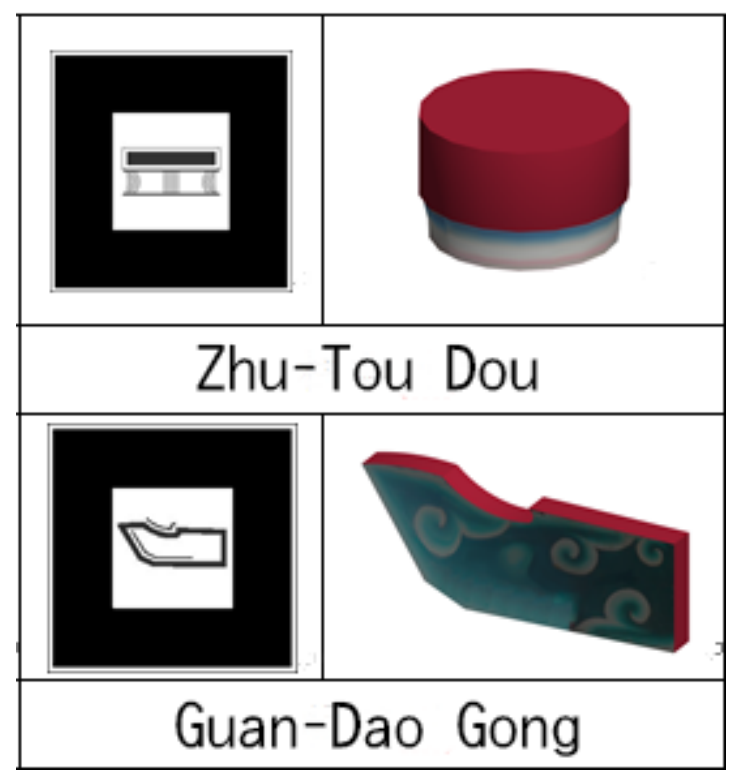

Figure 15. Zhu-Tau Dou and Guan-Dao Gong

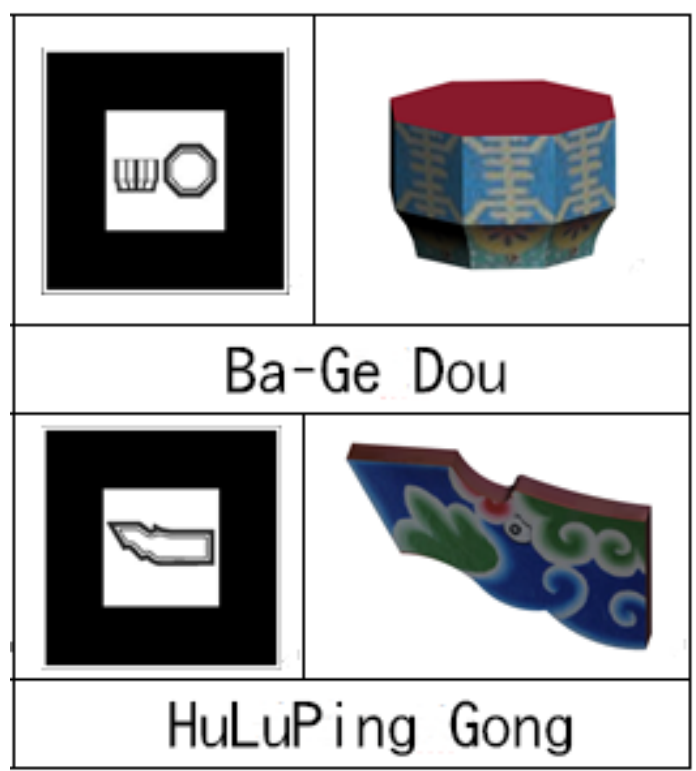

Figure 16. Ba-Ge Dou and HuLuPing Gong

\section{RAPID PROTOTYPING MODEL}

The RP model equipment used in this study is the V-Flash Desktop Modeler. All the model objects of the 3D model produced by the reverse engineering are integrated into one element (Element) after the post-production program. The print planning job not only integrates the exterior of the building, but also the detailed components of the interior of the building, including girders, beams, and columns and arches to avoid unnecessary stent produced during the printing of 3D model. Currently, the forming and strength problem still exists in the outcomes of the 3D printing of some of the detailed components of the building model for the limitation of equipment. However the rapid development of equipment will solve the cost and technical limitations. 

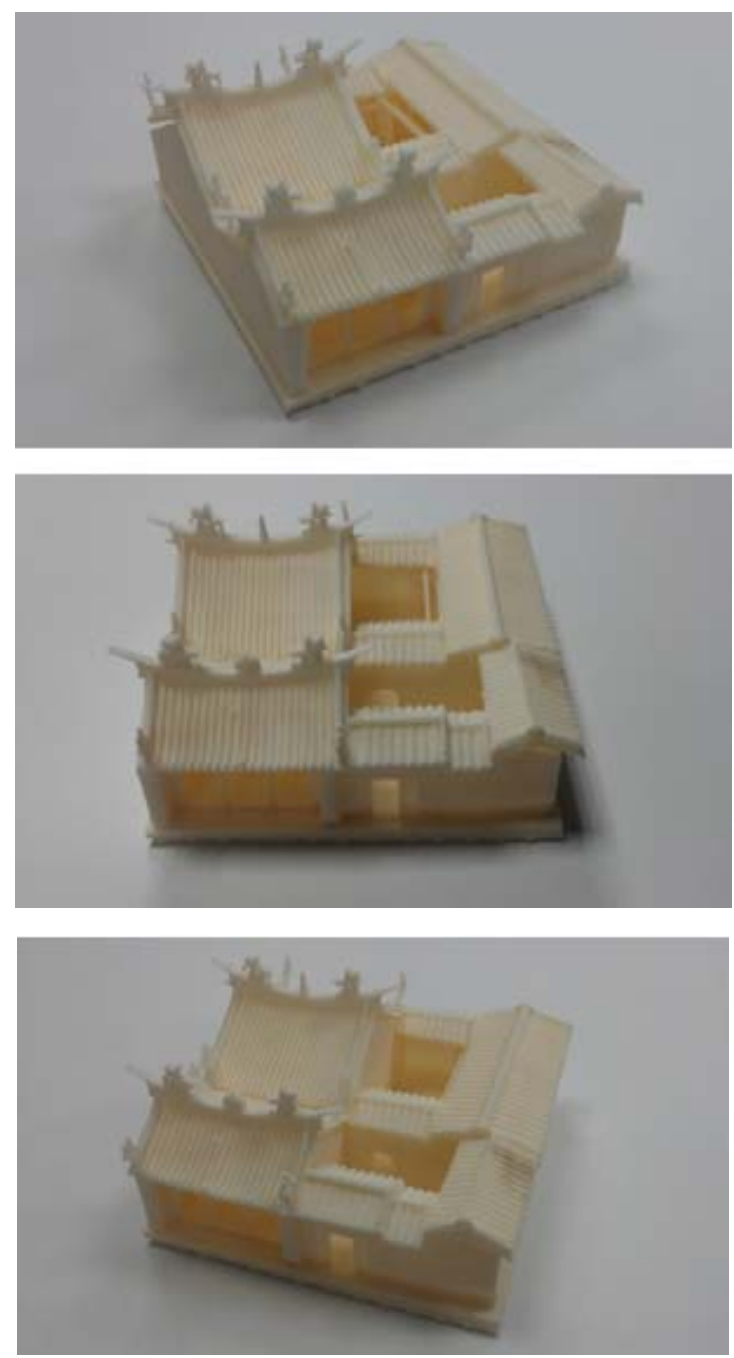

Figure 17. Exterior of Taipei Xia Hai City God Temple(RP)

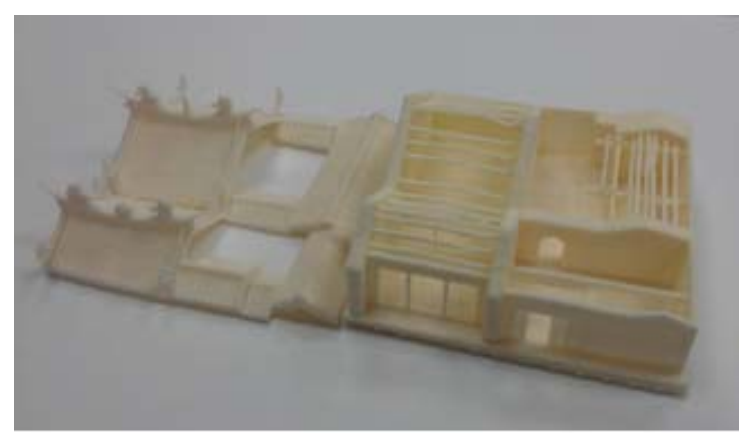

Figure 18. Interior of Taipei Xia Hai City God Temple(RP)

\section{CONCLUSION}

The digitalized preservation of historical building can be stored by the 3D Laser Scanning with the current size of heritage and historic buildings for actual recording and the point cloud format digitalization to enhance the mapping accuracy. The application of digitalization includes importing the architectural drawings by CAD software, using reverse engineering parameterization software to build the high accuracy and value- added 3D model. With the assistance of the related digital technology, the diverse value-added application is provided in preserving and navigating the Taipei Xia Hai City God Temple in this study. The learning of augmented reality image provides users the effectiveness of quick navigation and virtual space. In the future, RP can be combined with the products to keep promoting business and learning education and strengthening the application and management in the contents of the archives.

\section{ACKNOWLEDGEMENTS}

This study is sponsored by the Ministry of Science and Technology for 2010 Integrated Research Program (MOST99-2632-H-163-001-MY2)

\section{REFERENCES}

Quebec_Declaration,

http://www.international.icomos.org/quebec2008/quebec_declar ation/pdf/GA16_Quebec_Declaration_Final_EN.pdf, 2015.4.7

Shih, N.J., 2002. The Application of a 3D Scanner in the Representation of Building Construction Site., Proceedings of International Symposium on Automation and Robotics in Construction, 19 (ISARC), National Institute of Standards and Technology, Gaithersburg, Maryland.

Goldberg HE. Scan your would [RC1] with 3-D lasers. CADALYST Mag $402,2001: 20-8$.

Mayer, P. A. 1999" Computer media and communication : a reader" , Oxford, Oxford University Press.

Burdea, G. C. \& Coiffet, P. 2003 "Virtual reality technology (2nd ed.)", NJ: John Wiley \& Sons, Inc.

Shih, N.J., Wang, H.J., Lin, C.Y., Liau, C.Y., 2007. 3D scan for the digital preservation of a historical temple in Taiwan. Journal of Advances in Engineering Software 38(7), pp.501512. 